\title{
Low Density Multi-principal Element Alloy from Al-Mg-Ca-Si-B System
}

\author{
VICTOR GEANTA ${ }^{1}$, ROBERT CIOCOIU ${ }^{1}$, IONELIA VOICULESCU2* \\ IUniversity Politehnica of Bucharest, Materials Science and Engineering Faculty, 1-7 Polizu Str., 011061, Bucharest, Romania \\ 'University Politehnica of Bucharest, Engineering and Management of Technological Systems Faculty, Quality Engineering and \\ Industrial Technology Department, 313 Splaiul Independentei, Bucharest, Romania
}

\begin{abstract}
The scientific paper presents a numerical modeling of the chemical composition for the optimization of the multicomponent light alloys in the Al-Mg-Ca-Si-B system. The effects of the proportion of each chemical element on the main characteristics of the alloy based on the mixture rule and the correlation between the melting temperature and the modulus of elasticity were analyzed numerically. The model results has reveals that even other factors must be taken into account, i.e. the mechanical characteristics which varied significantly with changing of chemical compositions. A compromise was set, by slightly increasing the density to acquire better mechanical characteristics. The selected chemical composition was then used to obtain the new low density alloy. In current research stage we conclude that the as cast alloy comprises an inhomogeneous solid solution and complex oxides. Further studies are ongoing on the experimental alloy in various states (homogenization annealed and processed by plastic deformation).
\end{abstract}

Keywords: multi-component alloy, chemical composition, low density, microstructure

Light weight alloys are attractive for transportand energy industry where titanium alloys are the heaviest of this class used in engineering applications. Common structural alloys where weight is of main concern are based on a single principal element like Al, Mg or Ti. These conventional alloys have shown their limits and starting 2004 [1 - 3] a new class of alloys with excellent and customizable characteristics given by their unique composition and microstructure, named high entropy alloys (HEA) is developed.

Although 15 years have passed since their emergence, these alloys are loosely defined by Yeh [4] as composed of five or more principal elements in equimolar ratios. The definition expands the range by specifying that the principal elements concentration can range between 35 at $\%$ and 5 at $\%$. Minor element additions for properties customization are also accepted $[5,6]$. Along high entropy alloys the concept of multi-principal element alloys (MPEA) is introduced by Cantor [1]. In literature the terms are used interchangeably, Miracle [7] uses the term HEA when configurationally entropy or single-phase solid solution are the intent.

Since the aim of this research was not to obtain a Singlephase solid solution or the entropy, the terminology multicomponent principal element is more adequate for the alloy analyzed in this study.

The difficulty in raw material melting and procedural costs make HEA's currently inaccessible for large structural components therefore, using a similar approach, has been studied the possibility to obtain a low density MPEA from the Al-Mg-Ca-Si-B system, using Al as the base chemical element. There are know many aluminum alloys, but only several chemical elements are important as alloying elements in commercial alloys.

The choice of alloying elements is based on the mutual chemical compatibility and the possibility of obtaining the best technological properties [ 8 - 29]. For the Al-Mg-Ca-Si$B$ system, the solubility of the alloying elements is shown in table 1.

From the classical metallurgy point of view key aspects from binary and ternary systems are presented along the influence of each alloying element. The Al -Mg binaryalloy
Table 1

THE VALUES OF SOLUBILITY IN SOLID AND LIQUID STATE FOR ALLOYING ELEMENTS IN ALUMINUM $[8,11,15,30]$

\begin{tabular}{|c|c|c|}
\hline Element & $\begin{array}{c}\text { Liquid } \\
\text { solubility, \%wt }\end{array}$ & $\begin{array}{c}\text { Solid } \\
\text { solubility, \%wt }\end{array}$ \\
\hline $\mathrm{Mg}$ & 35.0 & 14.9 \\
\hline $\mathrm{Ca}$ & 7.6 & $<0.1$ \\
\hline Si & 12.6 & 1.65 \\
\hline $\mathrm{B}$ & 0.022 & $<0.001$ \\
\hline
\end{tabular}

system is complex: a eutectıc appears at $3 b \mathrm{wt} \% \mathrm{Mg}$ at $450^{\circ} \mathrm{C}$, a temperature at which $\mathrm{Mg}$ reaches its maximum solubility in $\mathrm{Al}$ at $14.9 \mathrm{wt} \%$. At room temperature $\mathrm{Mg}$ solubility in Al reaches roughly $1.7 \mathrm{wt} \%$. The addition of $\mathrm{Mg}$ in Al has an effect in decreasing alloy density by $0.5 \%$ for each $1 \mathrm{wt} \%$ of $\mathrm{Mg}[7,30]$.

In Mg-Ca binary alloys the microstructure is altered by Ca content: in as cast condition the dendritic cell size appears finer as Ca content increases (up to 10\%) and $\mathrm{MgCa}$, phase appears on grain boundaries [8 - 11, 24].

The Al -Si binary systems and Al-Mg-Si, Al-Si-Mg ternary systems are overviewed together. In binary Al-Si systems, $\mathrm{Si}$ forms coherent clusters in solid solution [12 - 14], Al - Si clusters in hypoeutectic alloys and primary silicon crystals in hypereutectic alloys [ 15]. In Al-Si alloys Mg is added for strengthening since the formation of $\mathrm{Mg}_{2} \mathrm{Si}$ precipitates occurs. From the Al-Mg-Si system the majority of the commercial alloys are intended for extrusion. Usually $\mathrm{Mg}$ and Si content is somewhat equal, $0.75 \mathrm{w} \% \mathrm{t}$ to $1.2 \mathrm{w} \% \mathrm{t}$, but, by adding excess $\mathrm{Si}$ an additional response to age hardening by $\mathrm{Mg}_{2} \mathrm{Si}$ precipitates refining [16] is gained. High silicon content, 5 to $20 \mathrm{wt} \% \mathrm{Si}$ in $\mathrm{Al}-\mathrm{Si}$-Mg alloys creates best casting properties. In the Al-B system a eutectic appears at $660^{\circ} \mathrm{C}$ at $0.022 \mathrm{wt} \% \mathrm{~B}$ between $\mathrm{Al}$ and $\mathrm{B}_{2} \mathrm{Al}$. Boron is mainly added to refine grain size or increase the electrical conductivity.

The selection of the chemical composition of this MPEA proves difficult given the contradictory and various effects

*email: ioneliav@yahoo.co.uk, Phone: 0744-327991 
of the alloying elements, but using a HEA approach we were able to establish and use the proportions to manufacture an alloy. In the current stage of the research microstructure investigations using scanning electron microscopy and chemical compositions using the energy dispersive X-ray spectrometer were performed.

\section{Experimental part}

Materials and methods

The paper presents the compositional analysis of an Al$\mathrm{Mg}-\mathrm{Ca}$-Si-B alloy system with low density. Lack of information regarding this alloying system has required a comparative study, based on a numerical analyze model, in order to determine optimal chemical composition for low density alloy. The study was performed by estimating of some alloy characteristics and investigating the influence of each alloying element on the density, melting temperature and elastic modulus of the resulting alloy.

Based on the results of calculations, an experimental chemical composition was chosen and then the alloy was obtained in a CTC50K15 induction heating furnace under argon protective atmosphere, using zirconia crucibles. The obtained alloy was studied, in as cast state, using a FEI Quanta Inspect Scanning electron microscope equipped with an energy-dispersive X-ray spectroscopy (EDS) installation to determine its microstructure and local chemical composition.

\section{Experimental alloy planning}

Using the data presented in table 1 a full factorial design of experiments with 4 factors ( $\mathrm{B}, \mathrm{Mg}, \mathrm{Si}, \mathrm{Ca}$ expressed in at $\%$ concentrations) was developed to observe the influence of each alloying element on the density and melting temperature which were estimated using a weighted mean method, based on the rule of mixtures $[17,18]$. Although deviation from the linearity of the rule is to be expected $[19,20]$, a rough property estimate is useful since no experimental data was available.

The elastic modulus was estimated via correlation using equation (1) proposed by M. F. Ashby [21]. Young's modulus value depends upon the alloy composition and the rule of mixture is limited when more phases appear, due to the fact that each phase exerts its own influence:

$$
C_{L}<\frac{E V_{m}}{R T_{m}}<C_{L}
$$

In equation (1) $E$ stands for elastic modulus in $\mathrm{GPa}, V_{m}$ the average volume per $\mathrm{kmol}$ in the structure, $R$ the gas constant in $\mathrm{kJ} \mathrm{kmol}^{-1} \mathrm{~K}^{-1}, T_{m}$ the melting temperature in $\mathrm{K}$ and $C_{1}$ and $C_{4}$ are dimensionless limits for various properties groups. In Ashby's study non-ferrous metals and alloys have limits values for the elastic modulus from 4.6 GPa to 570 $\mathrm{GPa}$. In this study the limits for the elastic modulus were set according to those of some possible binary phases which were determined by Wang [22] in a similar system, as follows: $\mathrm{Mg}_{17} \mathrm{Al}_{2}$ of $70.12 \mathrm{GPa}, \mathrm{Mg}_{2} \mathrm{Ca}$ of $43.71 \mathrm{GPa}, \mathrm{Al}_{2} \mathrm{Ca}$ of $103.59 \mathrm{GPa}$ while the elastic modulus of aluminum is roughly $70 \mathrm{GPa}$, thus setting the lower limit at roughly $43 \mathrm{GPa}$ and the higher one at $103 \mathrm{GPa}$.

The uncertainty of this rule, estimated according to Ashby's work is 1.54. To increase the safety factor for our estimations, the lower value as reference for all computations has been used (table 2 ).

In the designed experimentboron influence was studied on a 1 (low) to 5 (high) at\% while $\mathrm{Mg}, \mathrm{Si}$ and Ca were studied on a 10 (low) to 20 (high) at\% composition interval.

Aluminum content was varied as necessary to balance the composition, while its main characteristics (density, melting temperature and elastic modulus) were established as constants in the response equations for each characteristic. By performing the computations on a randomized order shown in table 3, results were estimated on model imposed theoretical chemical compositions.

\begin{tabular}{|l|c|c|c|c|c|}
\hline \multirow{2}{*}{ Characteristics } & \multicolumn{5}{|c|}{ Chemical elements } \\
\cline { 2 - 6 } & $\mathrm{B}$ & $\mathrm{Mg}$ & $\mathrm{Al}$ & $\mathrm{SI}$ & $\mathrm{Ca}$ \\
\hline Atomic weight & 10.811 & 24.305 & 26.98154 & 28.0855 & 40.078 \\
\hline Density, g/cm & & & & & \\
\hline Melting temperature, ${ }^{\circ} \mathrm{C}$ & 2.46 & 1.738 & 2.66 & 2.33 & 1.55 \\
\hline Atomic radius, pm & 2075 & 650 & 660.32 & 1414 & 842 \\
\hline Valence electron concentration & 2.04 & 1.31 & 1.61 & 1.9 & 1 \\
\hline
\end{tabular}

Table 2

PHYSICAL DATA USED FOR COMPUTATIONS [22]

RUN ORDER AND INFLUENCE FACTOR VALUES USED IN THE DESIGN OF EXPERIMENT

\begin{tabular}{|c|c|c|c|c|c|}
\hline Standard order & Run order & at\% B & at\% Mg & at\% Si & at\% Ca \\
\hline 10 & 1 & High & Low & Low & High \\
\hline 1 & 2 & Low & Low & Low & Low \\
\hline 7 & 3 & Low & High & High & Low \\
\hline 13 & 4 & Low & Low & High & High \\
\hline 14 & 5 & High & Low & High & High \\
\hline 8 & 6 & High & High & High & Low \\
\hline 12 & 7 & High & High & Low & High \\
\hline 15 & 8 & Low & High & High & High \\
\hline 5 & 9 & Low & Low & High & Low \\
\hline 4 & 10 & High & High & Low & Low \\
\hline 9 & 11 & Low & Low & Low & High \\
\hline 11 & 12 & Low & High & Low & High \\
\hline 2 & 13 & High & Low & Low & Low \\
\hline 6 & 14 & High & Low & High & Low \\
\hline 3 & 15 & Low & High & Low & Low \\
\hline 16 & 16 & High & High & High & High \\
\hline
\end{tabular}


The models generated from this runs order were applied for the study of the influence of the alloying elements concentrations on the density, melting temperature and elastic modulus of the alloy.

Starting with the estimated density of the alloy $\left(\rho_{\text {allor }}\right)$, the resulting response is described by equation (2) in un coded units, where B, Mg, Si and $\mathrm{Ca}$ are the concentration of the element in atomic percent.

$2.66-0.0015 B-0.012 \mathrm{Mg}-0.004 \mathrm{Si}-0.021 \mathrm{Ca}=\rho_{\text {alloy }}$

In equation (2) second, third and fourth order interactions were neglected given their low coefficient values $\left(10^{-5}-10^{-9}\right)$ when compared to ones of main factors. The higher order interactions have such low values because the rule of mixture generates a linear variation.

Using equation (2) response surfaces were constructed and shown in figure 1. Because four factors can be varied, the surface construction required that 2 factors have fixed values (these are specified in the legend below), while the others have been varied. In figure la the concentrations of Si and Ca were fixed at 10,15 and 20 at\% while the concentration of $\mathrm{B}$ and $\mathrm{Mg}$ was varied from low to high values. In Figure $1 \mathrm{~b}$ same procedure was applied, but this time $B$ and $\mathrm{Mg}$ concentrations were fixed at values shown in the legend, while Si and Ca concentrations were varied from low to high.

The results show that a major influence in density decrease is played by Ca concentration, while $\mathrm{Mg}$ is second as importance. Boron and Silicon have a lower impact on density decrease when compared to Ca and Mg. Regarding the melting temperature ( $T_{\text {melt }}$ ) of the alloy, the influence of each of the alloying elements can be described using equation (3).

$660.320+14.15 B-0.10 \mathrm{Mg}+7.54 \mathrm{Si}+1.81 \mathrm{Ca}=T_{\text {melt }}$

Also, in equation (3) the second, third and fourth order interactions are neglected given their low coefficient values $\left(10^{-15}-10^{-18}\right)$. The response surfaces constructed in the same manner as described previously are shown in figure 2.

According to the variations of the response surface it appears that B has the largest role in increasing melting temperature, second being $\mathrm{Si}$ and third $\mathrm{Ca}$. Magnesium has an opposite effect, because it lowers (almost insignificantly) the melting temperature of the alloy.

Studying the elastic modulus evolution of the alloy $\left(E_{\text {alloy }}\right)$, its variation can be described by equation (4):

$$
70.00-0.70 B-0.25 \mathrm{Mg}-0.23 \mathrm{Si}-0.50 \mathrm{Ca}=E_{\text {alloy }} \text { (4) }
$$

Again, second, third and fourth order interactions are omitted given their low coefficient values $\left(10^{-16}-10^{-19}\right)$. The response surfaces obtained by alloying element concentration variation are shown in figure 3 .

Alloying element concentration increase tends to lower the elastic modulus of the alloy; most significant influences are shown by B followed by Si while Mg and Si are on par. These results combined allowed an alloy composition to be established for the experimental research. The goal of achieving a lower density alloy was slightly altered since
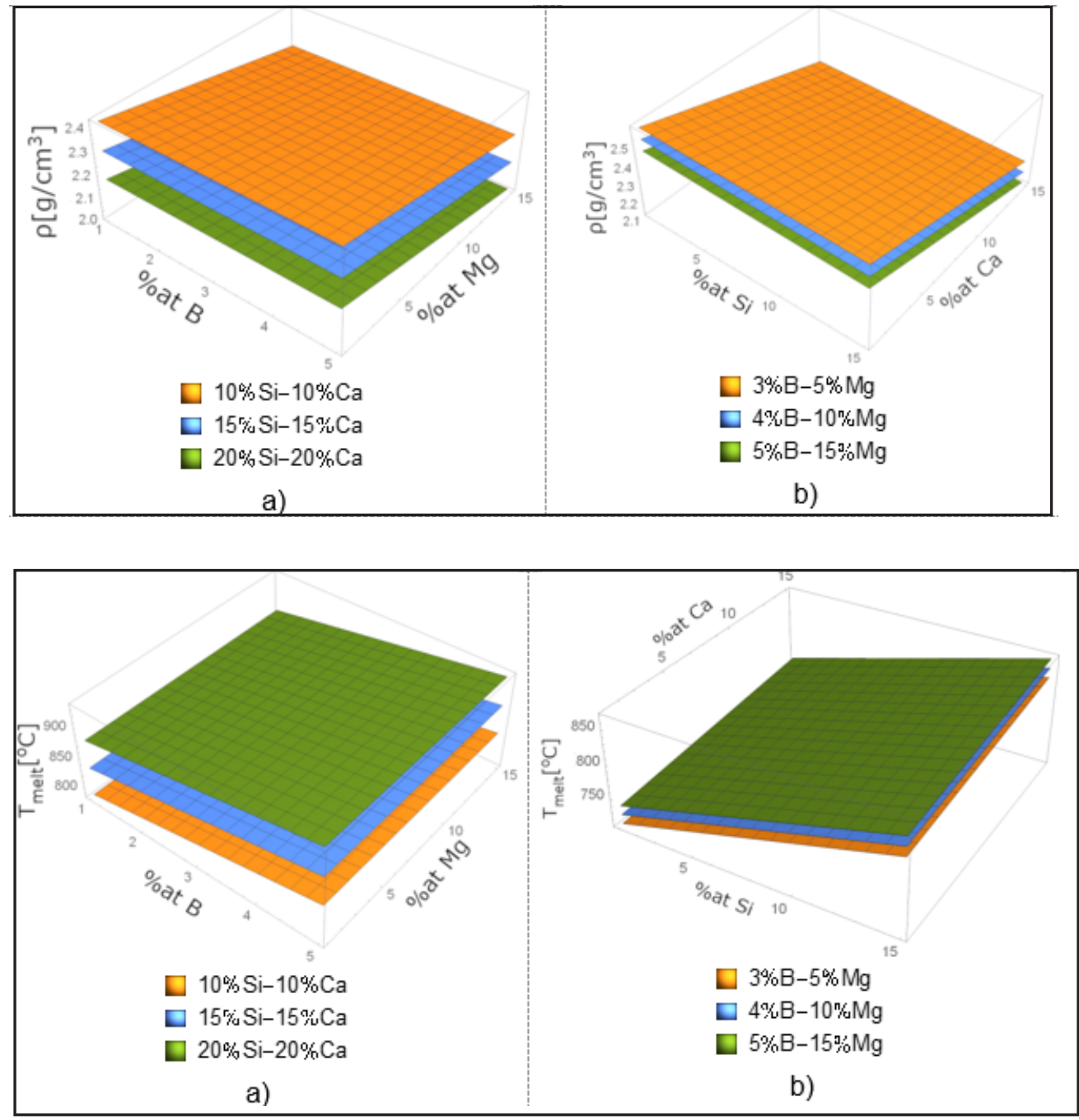

REV.CHIM.(Bucharest) 70 No. 7 • 2019
Fig. 1. Response surface showing factor influence on the density of the alloy.

Fig. 2. Response surface showing factor influence on the melting temperature of the alloy. 


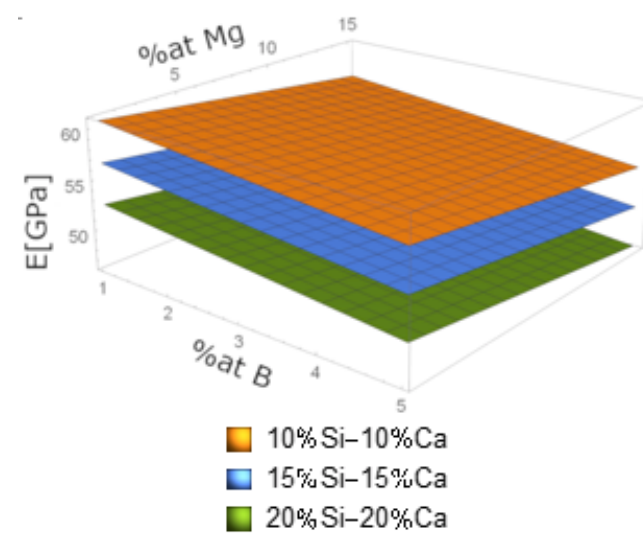

a)

rigidity was also desired. The melting temperature was considered as an optional requirement.

A compromise was inevitable: a sacrifice on density was necessary in order to achieve higher mechanical characteristics, thus the alloy chosen for experimental elaboration was not the lightest in this system. Boron lowers the elastic modulus and density, but increases melting temperature - a concentration of around 5-7 wt\% at was considered as optimum. Magnesium decrease all the parameters above, but its presence in aluminum alloys is proven beneficial for cold working, 15-20 wt\% was taken into account and $15-20 \mathrm{wt} \%$ for silicon and $10-15 w \mathrm{t} \%$ calcium. Aluminum concentration should balance to $100 \mathrm{w} \%$.

\section{Alloy preparation}

To obtain the alloy with the chemical composition within proposed ranges alloying elements and pre-alloys were used, as presented in table 4. Experimentally $30 \mathrm{~g}$ batches can be made in available installations. Weighing individual
Fig. 3. Response surface showing factor influence on the elastic modulus of the alloy.

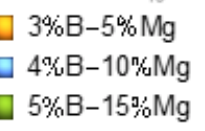

b)

alloying elements, $5 \mathrm{~g}$ of $\mathrm{Mg}$, $\mathrm{Ca}$ and Si were added as pellets and an Al-B with $7 \%$ wt $B$ alloy was added, thus resulting $0.8 \mathrm{~g} \mathrm{~B}$ and $14.2 \mathrm{~g} \mathrm{Al}$. The experimental alloy expected chemical composition would comprise 47.33 wt\% Al, 16.66 wt $\% \mathrm{Mg}, 16.66 \mathrm{wt} \% \mathrm{Si}, 16.66 \mathrm{wt} \% \mathrm{Ca}$ and $2.69 \mathrm{wt} \% \mathrm{~B}$ as weight.

Converting the values alloy characteristics were determined by direct computations and using the models. The results are shown, for comparison, in table 5.

A good agreement between direct computations and the models has been observed. The alloy was prepared in a CTC50K 15 induction heating furnace under argon protective atmosphere using zirconia crucibles (fig. 4). The raw materials were homogenized and placed simultaneously in the zirconia crucible.

After a preheating stage at $450^{\circ} \mathrm{C}$, the materials were melted at $650-680^{\circ} \mathrm{C}$ followed by slow cooling, all the processes being performed under inert protective atmosphere. Losses by oxidation were estimated at $2 \%$, despite the protective argon atmosphere.

\begin{tabular}{|c|c|c|}
\hline Alloying element & Materials details & Average purity, \% \\
\hline Aluminum & $2-5 \mathrm{~mm}$ pellets & 99.5 \\
\hline Magnesium & $2-5 \mathrm{~mm}$ pellets & 99.5 \\
\hline Calcium & $2-6 \mathrm{~mm}$ pellets & 98.5 \\
\hline Silicon & technical silicon powder & 99.5 \\
\hline Boron & Al - B pre-alloy containing 7\% Boron & - \\
\hline
\end{tabular}

Table 4

MATERIALS USED FOR EXPERIMENTAL ALLOY

\begin{tabular}{|c|c|c|c|}
\hline & Density, $\mathrm{g} / \mathrm{cm}^{3}$ & $\begin{array}{c}\text { Melting } \\
\text { temperature, }{ }^{\circ} \mathrm{C}\end{array}$ & $\begin{array}{c}\text { Elastic } \\
\text { Modulus, GPa }\end{array}$ \\
\hline Direct computation & 2.17 & 894.86 & 51.44 \\
\hline Model computation & 2.13 & 894.98 & 51.34 \\
\hline
\end{tabular}

Table 5

COMPARISON OF PREDICTED ALLOY CHARACTERISTICS

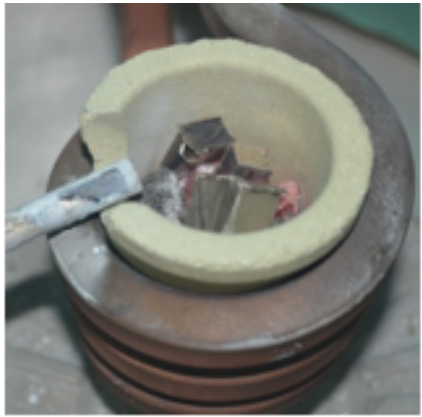

a)

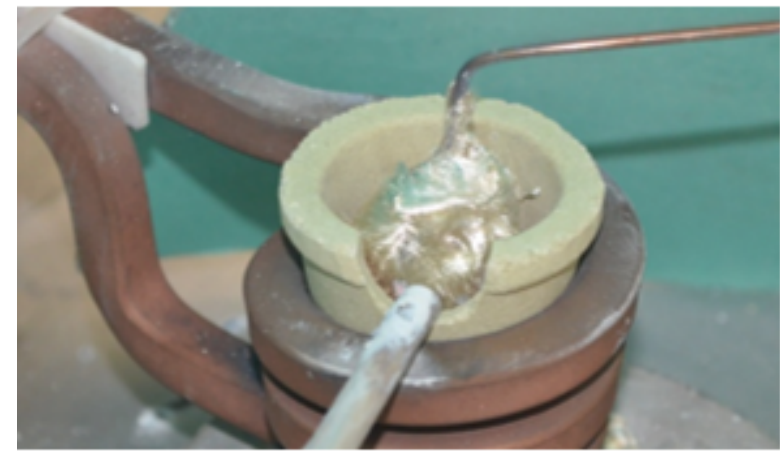

b)

Fig. 4. Raw materials (a) and alloy melted by induction in the ceramic crucible (b). 
Table 6

CHEMICAL COMPOSITION ON THE AREA OF INTEREST IN FIGURE 5b AND FIGURE $5 c$

\begin{tabular}{|c|c|c|c|c|c|c|}
\hline \multirow{2}{*}{ Element } & \multicolumn{2}{|c|}{$\%$ wt } & \multicolumn{2}{|c|}{$\%$ at } & \multicolumn{2}{|c|}{ Error \% } \\
\hline & b) & c) & b) & C) & b) & c) \\
\hline $\mathrm{Mg}$ & 8.55 & 4.79 & 9.62 & 5.31 & 3.36 & 5.58 \\
\hline Al & 72.17 & 77.26 & 73.17 & 77.13 & 3.39 & 3.81 \\
\hline Si & 13.54 & 3.95 & 13.19 & 3.79 & 8.93 & 11.13 \\
\hline $\mathrm{Ca}$ & 5.67 & - & 3.87 & - & 4.84 & - \\
\hline $\mathrm{Fe}$ & 1.14 & 8.16 & 0.57 & 3.93 & 12.11 & 3.18 \\
\hline
\end{tabular}

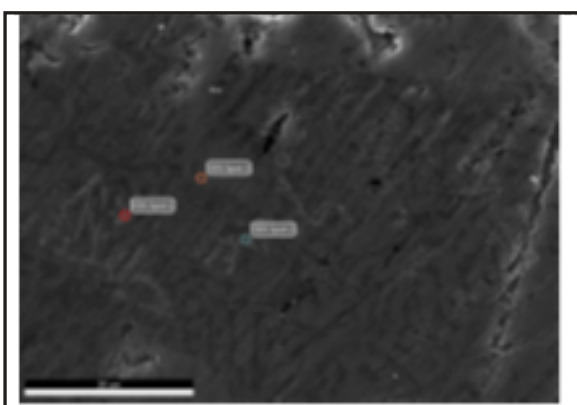

a)

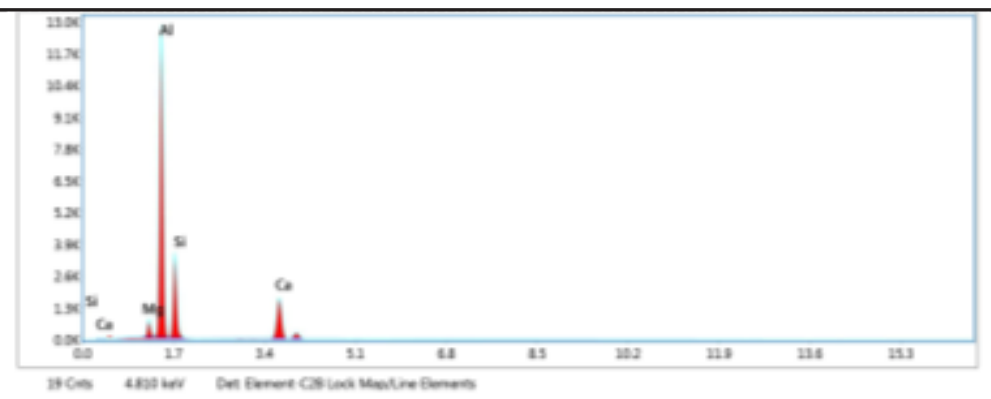

b)

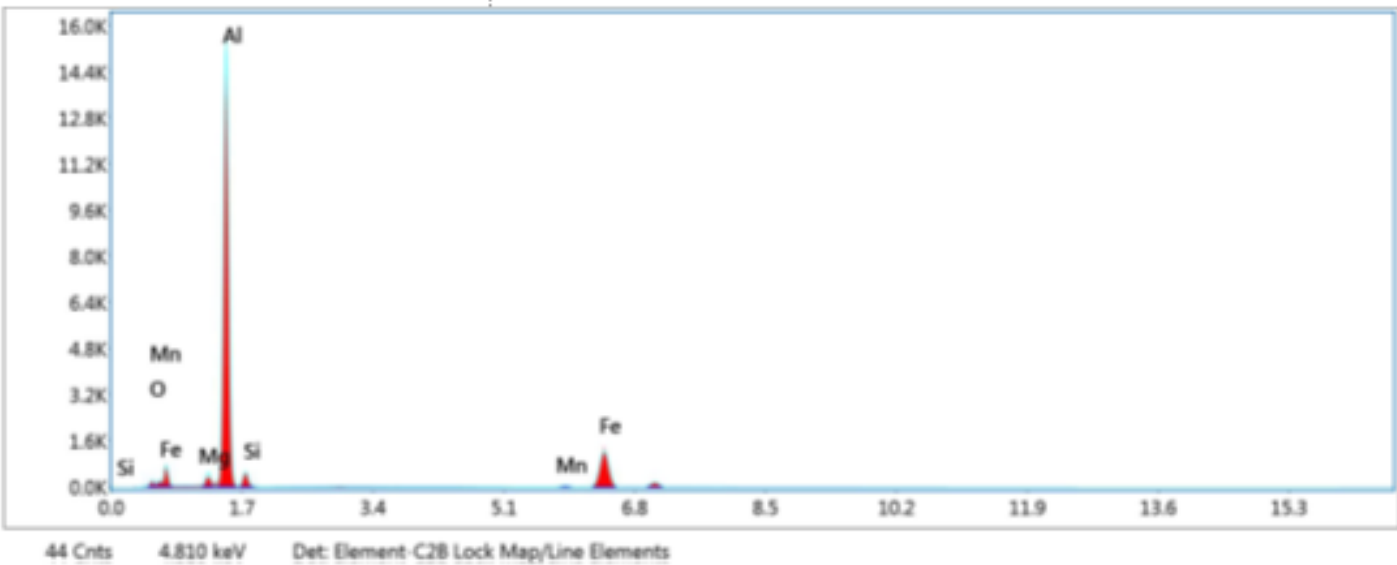

c)

Fig. 5. Experimental alloy microstructure (a) and EDS spectra of micro-zones ( $b$ and $c$ )

\section{Results and discussions}

Using the scanning electron microscope FEl-Quanta Inspect $\mathrm{S}$ equipped with an EDAX Z2e analyzer the microstructure and local chemical composition were studied on metallographic prepared specimens. In Figure 5 the microstructure can be observed with EDS spectra on a region of interest.

The microstructure presented in figure $5 a$ reveals a typical as cast dendritic microstructure and chemical compounds. The material is inhomogeneous with obvious segregation, pores and microcavities. The quantification of the spectra shown in Figure $5 b$ and Figure $5 c$ revealed the chemical composition presented in table 6 for microzones of interest.

The presence, in small amounts, of Fe was observed and can be traced, most likely, to the Al-B pre-alloy used. Boron could not be quantified via EDS because of method limitation when dealing with elements with low atomic number $Z$. The element repartition suggests that inter- dendrite regions are richer in magnesium, while inside the dendrite higher silicon and calcium contents are present. In the compound iron, silicon, magnesium and oxygen were found, similar to a natural occurrence reported by Neumann [23]. More electronegative elements ( $\mathrm{Al}$ and $\mathrm{Mg}$ ) are rejected in the interdendritic regions [1], while boron, the element with highestelectronegativity, unfortunately could not be accurately detected by EDS. Based upon these results an inhomogeneous solid solution and inter-metallic compounds can be inferred to be present in the experimental as-cast alloy.

\section{Conclusions}

According to the aim of the research an alloy from the multi elements Al-Mg-Ca-Si-B system was manufactured, despite difficulties given by the oxidation tendencies of alloying elements. The alloy was studied by SEM and EDS and the results showed a multi-phase alloy with an 
inhomogeneous solid solution and complex inter-metallic compounds.

The current results are satisfactory since the production method yields goods results. Based on these results, HEA with $\mathrm{Al}, \mathrm{Mg}, \mathrm{Ca}$ and $\mathrm{Si}$ in equimolar ratios can be obtained, by varying $B$ content. In this situation the results predict a lower density, ranging, depending on composition, from 1.7 to $1.9 \mathrm{~g} / \mathrm{cm}^{3}$ with the value of elastic modulus in the $45 \pm 3 \mathrm{GPa}$ range. The current experimental alloy will be gone through various processing routes and studied to establish the optimal processing route -microstructure properties relation.

Acknowledgment: This work was supported by a grant of the Romanian Ministry of Research and Innovation, CCCDI - UEFISCDI, project number PN-III-P1-1.2-PCCDI-2017-0875-20/2018 (HEAPROTECT).

\section{References}

1.CANTOR B., CHANG I.T.H., KNIGHT P., VINCENT A.J.B., Microstructural development in equiatomic multicomponent alloys. Mat Sci Eng a-Struct 375, 2004, 213-218.

2.CHEN T.K., SHUN T.T., YEH J.W., WONG M.S., Nanostructured nitride films of multi-element high-entropy alloys by reactive DC sputtering, Surf Coat Tech 188, 2004,193-200.

3.HSU C.Y., YEH J.W., CHEN S.K., SHUN T.T., Wear resistance and high-temperature compression strength of Fcc CuCoNiCrAl0.5Fe alloy with boron addition, Metall. Mater Trans A 35A 2004,1465-1469.

4.YEH J.W., CHEN S.K., LIN S.J., GAN J.Y., CHIN T.S., SHUN T.T., et al. Nanostructured high-entropy alloys with multiple principal elements: Novel alloy design concepts and outcomes, Adv. Eng. Mater 6, 2004, 299-303.

5.YEH J.W., Recent progress in high-entropy alloys. Ann Chim-Sci Mat 31, 2006, 633-48.

6.MACDONALD B.E., FU Z., ZHENG B., CHEN W., LIN Y., CHEN F., et al. Recent Progress in High Entropy Alloy Research, Jom-Us 69, 2017, 2024-2031.

7.MIRACLE D.B., SENKOV O.N., A critical review of high entropy alloys and related concepts, Acta Mater 122, 2017, 448-511.

8.MONDOLFO, L.F., Aluminum Alloys: Structure and Properties, Butterworths, London, 1976.

9.BITA A.I., ANTONIAC I., CIUCA I., Potential use of Mg-Ca alloys for orthopedic applications, UPB Sci. Bull. 78, 2016, 173-84.

10.RAD H.R.B., IDRIS M.H., KADIR M.R.A., FARAHANYS., Microstructure analysis and corrosion behavior of biodegradable Mg-Ca implant alloys, Mater Design 33, 2012, 88-97.

11.BITAA.I., ANTONIACA., COTRUT C., VASILEE., CIUCA I., NICULESCU

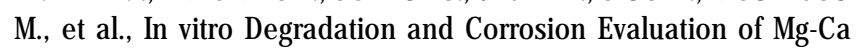
Alloys for Biomedical Applications, J Optoelectron Adv Mat. 18, 2016, 394-398.

12.HAYOUNE A., A Calorimetric Study of the Precipitation Hardening Mechanisms in an Al-Cu-Mg-Si Alloy, Int J Mod Phys B, no.27, 2013. 13.BANERJEE S., ROBI P.S., SRINIVASAN A., Calorimetric study of precipitation kinetics of Al-Cu-Mg and Al-Cu-Mg-0.06 wt.\% Sn alloys, Met Mater Int 16, 2010, 523-531.

14.DUTTA I., ALLEN S.M., A Calorimetric Study of Precipitation in Commercial Aluminum Alloy-6061, J Mater Sci Lett 10, 1991, 323-326. 15.ZHANG D.L., Precipitation of excess silicon during heat treatment of cast Al-7wt\%Si-0.4wt\%Mg alloy, Aluminium Alloys: Their Physical and Mechanical Properties 217, Pts 1-3, 1996, 771-776.
16.LANGERWERGER, J., Influence of heat treatment practice on extrudability and properties of AlMgSi alloy sections, Aluminium Technology ' 86 , ed. T. Sheppard, London, The Institute of Metals, 1986, p. 216-222.

17.YANG X., ZHANG Y., Prediction of high-entropy stabilized solidsolution in multi-component alloy, Mater Chem Phys 132, 2012, 233238.

18.YANG X., CHEN S.Y., COTTON J.D., ZHANG Y., Phase Stability of Low-Density, Multiprincipal Component Alloys Containing Aluminum, Magnesium, and Lithium. J om-Us 66, 2014, 2009-2020.

19.BOLCU, D., STANESCU, M.M., CIUCA, I., TRANTE, O., BRANZEI, M., New Relations for the Calculus of Elastical and Mechanical Characteristics of Polyester Composites Reinforced with Randomly Dispersed Fibers, Mat. Plast, 46, 2009, p. 206-210.

20.STANESCU, M.M., BOLCU, D., CIUCA, I., RIZESCU, S., TRANTE, O., BAYER M., The Nonlinear Mechanical Behaviour of Composite Materials Reinforced with Carbon Fiber Weaves, Mat. Plast, 47, 2010, p. 103-108.

21.ASHBY M.F., Checks and estimates for material properties I. Ranges and simple correlations, P Roy Soc a-Math Phy 454, 1998, 1301-1321. 22.WANG F., SUN S.J ., YU B., ZHANG F., MAO P.L., LIU Z., First principles investigation of binary intermetallics in Mg-Al-Ca-Sn alloy: Stability, electronic structures, elastic properties and thermodynamic properties, T Nonferr Metal Soc 26, 2016, 203-212.

23.NEUMANN E.R., SVENSEN H.H., POLOZOV A.G., Hammer 0. Formation of Si-Al-Mg-Ca-rich zoned magnetite in an end-Permian phreatomagmatic pipe in the Tunguska Basin, East Siberia, Miner Deposita 52, 2017, 1205-1222.

24.GEANTA V., VOICULESCU I., KELEMEN H., KELEMEN G., Obtaining of light biocompatible magnesium alloys using levitation equipment under controlled argon atmosphere, XXIII INTERNATIONAL CONFERENCE ON MANUFACTURING, IOP Conference Series-Materials Science and Engineering 448, 2018, UNSP 012004, DOI: 10.1088/1757899X/448/1/012004.

25.VOICULESCU, I., GEANTA, V., STEFANOIU, R., PATROI, D., BINCHICIU, H., Influence of the Chemical Composition on the Microstructure and Microhardness of AlCrFeCoNi High Entropy Alloy, Rev. Chim. (Bucharest) 64, no. 12, 2013, p.1441-1444.

26.GEANTA, V., VOICULESCU, I., MILOSAN, I., ISTRATE, B., MATES, I. M., Chemical Composition Influence on Microhardness, Microstructure and Phases Morphology of $\mathrm{Al}_{\mathrm{x}} \mathrm{CrFeCoNi}$ High Entropy Alloys, Rev. Chim. (Bucharest) 69, no. 4, 2018, p.798-801.

27.GEANTA, V., VOICULESCU, I., ISTRATE, B., VRANCEANU, D.M., CIOCOIU, R., COTRUT, C.M., The Influence of Chromium Content on the Structural and Mechanical Properties of AlCrxFeCoNi High Entropy Alloys, International J ournal of Engineering Research in Africa 37, 2018, p.23-28.

28.VOICULESCU, I., GEANTA, V., IONESCU, M. Effects of heat treatments on the microstructure and microhardness of AlxCrFeNiMn alloys, The Annals of Dunarea de Jos University of Galati, fascicle XII 26, 2015, p.5-11.

29.FAZAKASE., VARGA B., GEANTA V., BERECZT., JENEI P., VOICULESCU I., COSNITA M., STEFANOIU R., Microstructure, thermal, and corrosion behavior of the AlAgCuNiSnTi Equiatomic multicomponent alloy, Materials 12, Issue 6, 2019, Article Number: 926, DOI: 10.3390/ ma12060926.

30.NARDIN M. Constitution of binary alloys (Constitutia aliajelor binare), Bucuresti 2002, ISBN 973-0-02814-1.

Manuscript received: 10.01 .2019 